\title{
À VISTA OU À PRAZO - DOIS LADOS DE UMA MESMA MOEDA: ENSINO DE EDUCAÇÃO FINANCEIRA ESCOLAR UTILIZANDO DISPOSITIVOS MÓVEIS
}

\section{SPOT OR FORWARD: TWO SIDES OF THE SAME COIN - FINANCIAL SCHOOL EDUCATION TEACHING USING MOBILE DEVICES}

\author{
Fausto Daniel Alves Fernandes \\ Universidade Federal de Juiz de Fora - UFJF/faustinoctu@gmail.com \\ Liamara Scortegagna \\ Universidade Federal de Juiz de Fora - UFJF/liamara@ice.ufjf.br \\ Eduardo Barrére \\ Universidade Federal de Juiz de Fora - UFJF/Eduardo.barrere@ice.ufjf.br
}

\begin{abstract}
Resumo
O presente artigo traz a discussão sobre o uso dos Dispositivos Móveis na sala de aula de Matemática. Neste sentido, reconhece-se a importância que seu uso esteja diretamente relacionado a uma proposta pedagógica, e se vislumbra na elaboração e aplicação de tarefas uma possibilidade para que se constitua tal relação. Para exemplificar é apresentada a tarefa de Educação Financeira Escolar "À vista ou à prazo - dois lados de uma mesma moeda", que tem o intuito de motivar os estudantes à tomada de decisão, de forma crítica, em situações que envolvam dinheiro, assim, retratando o objetivo principal deste artigo. Neste debate fica evidente a existência de contribuições positivas dos dispositivos móveis nos processos de ensino e de aprendizagem, desde que seu uso não seja simplesmente liberado sem que haja um direcionamento aos estudantes. Destaca-se, ainda, que tarefas são um dos meios, mas não o único, de se integrar as tecnologias móveis presentes na sala de aula e, por isso, vale-se deste espaço para convidar a outras reflexões sobre o uso de tais tecnologias.
\end{abstract}

Palavras-chave: Dispositivos móveis, Educação financeira escolar, Educação matemática.

\section{Abstract}

The present article brings the discussion about the use of Mobile Devices in the Mathematics classroom. In this sense, it is recognized the importance that its use is directly related to a pedagogical proposal and it is envisaged in the elaboration and application of tasks a possibility for such a relation to be constituted. To exemplify, the task of School Financial Education "Spot or forward - two sides of the same coin" is presented, which is intended to motivate students to make a decision in a critical way, in situations that involve money, thus 
portraying the main purpose of this article. In this debate it is evident that there are positive contributions of the mobile devices in the teaching and learning processes, provided that their use is not simply released without a direction to the students. It should also be noted that tasks are one of the means, but not the only means of integrating the mobile technologies

Keywords: Mobile devices, School financial education, Mathematical education.

\section{Introdução}

O texto ora apresentado compõe um quadro de investigação que discute sobre as Tecnologias da Informação e Comunicação (TICs) num contexto de Educação Matemática. Neste cenário, encaminha-se a reflexão sobre a Aprendizagem Móvel, um conceito importante, posto que se tem o olhar direcionado para os Dispositivos Móveis Pessoais (DMP) na sala de aula de Matemática. Para tanto, é evocada para dentro desta sala de aula uma "tarefa", que tem o papel de impulsionar os estudantes à tomada de decisão em situações que envolvam dinheiro, isto é, o que está posto em pauta é a construção de uma tarefa de Educação Financeira Escolar em que a tecnologia utilizada é o dispositivo móvel, a partir de uma perspectiva da Educação Matemática.

Tais temáticas emergem da percepção da disparidade existente entre a realidade interior aos muros das escolas públicas da Educação Básica com seu exterior, isso no que diz respeito ao uso da tecnologia. Frente a isso, surge a inquietação com respeito ao uso das tecnologias nas aulas de Matemática e alguns obstáculos são encontrados, como a ausência de computadores para atender a uma turma e, diante disto, uma alternativa que parece bem exequível é a inserção dos smartphones dos próprios alunos e professor como dispositivo tecnológico de apoio as atividades durante as aulas. No entanto, observa-se uma reduzida disponibilidade de material de apoio para tal, e em alguns casos, dependendo do conteúdo, nenhum material está disponível.

Ao relacionar a Aprendizagem Móvel, ou seja, o uso de DMP, com o ensino da Educação Financeira Escolar, assume-se a proposta de Educação Financeira Escolar defendida por Silva e Powell (2013), a qual foi construída pensando na realidade das escolas e compreendida como parte da Educação Matemática. Para os autores, a Educação Financeira Escolar se constitui de um conjunto de informações sobre o universo do dinheiro com o objetivo de estimular uma compreensão sobre finanças e economia. Vale aqui destacar que a aprendizagem móvel (Mobile Learning) não ocorre somente na área de educação matemática, outras áreas também estão adotando esse tipo de aprendizagem, como pode ser visto no trabalho de Almeida e Araújo Jr, (2018).

Considerando os elementos conceituais expostos, definiu-se como objetivo da investigação a discussão sobre o uso dos dispositivos móveis na sala de aula de Matemática dentro de um contexto de ensino da Educação Financeira Escolar e propor a tarefa "À vista ou à prazo - dois lados de uma mesma moeda", com o intuito de motivar os estudantes à tomada de decisão, de forma consciente, em situações que envolvam 
dinheiro.

O artigo está organizado em cinco seções. Na introdução, os autores fazem uma breve apresentação do estudo e contextualização. Na seção 2, são apresentados dados e a discussão sobre o uso de dispositivos móveis na sala de aula de matemática. Na seção 3, é feita a exposição das bases teóricas da pesquisa, incluindo a aprendizagem móvel, Educação Financeira Escolar e tomada de decisão. Traz-se na seção 4 a seleção dos aplicativos para uso nos dispositivos móveis e o processo de produção e aplicação da tarefa "À vista ou à prazo - dois lados de uma mesma moeda". Por fim, a conclusão apresenta a perspectiva dos autores a respeito dos conceitos abordados.

\section{0 uso de dispositivos móveis na sala de aula de matemática}

Não é novidade a existências de estudos argumentando a eficiência das tecnologias quando inseridas dentro de propostas pedagógicas, ao ponto de colaborarem na construção de políticas públicas que incentivam a inserção das TICs na educação. Tal fato pode ser observado entre os objetivos da Política Nacional de Formação dos Profissionais da Educação Básica, conforme consta no art. $3^{\circ}$ do Decreto $n^{\circ}$ 8.752/2016: "promover a atualização teórico-metodológica nos processos de formação dos profissionais da educação básica, inclusive no que se refere ao uso das tecnologias de comunicação e informação nos processos educativos". Isto acompanhado de um conjunto de ações para que as escolas possuam laboratórios de informática e profissionais que monitorem estes espaços, permitindo que os professores usufruam deles para desenvolverem atividades com seus alunos.

Ainda assim, as TICs não estão presentes numa parcela significativa das dinâmicas do cotidiano da sala de aula é um dos fatores que merecem destaque, neste sentido diz respeito à falta de equipamento para uso, ou melhor, a indisponibilidade em condições para uso. E, por outro lado, Nagumo (2014) afirma que a escola encontra num contexto em que os dispositivos móveis invadem a sala de aula através dos estudantes, que levam para dentro desse espaço seus smartphones e os utilizam, numa parcela significativa de vezes, em atividades não relacionadas aos processos de ensino e aprendizagem. Diante dessa realidade, as instituições de ensino unidas ao poder público têm se unido em busca de regulamentar tal uso, a fim de evitar que isso gere transtornos individuais ou coletivos. Ressalta-se ainda que tais regulamentações se limitam a proibir a utilização dos dispositivos móveis no ambiente escolar em qualquer situação, por exemplo, o art. $1^{\circ}$ da Lei 14.486, de 9 de dezembro de 2002 aprovado pela Câmara dos Deputados de Minas Gerais, que traz em seu texto: "Fica proibida a conversação em telefone celular e o uso de dispositivo sonoro do aparelho em salas de aula, teatros, cinemas e igrejas".

Em particular, mas não muito diferente, na Educação Matemática brasileira a tecnologia tem seu potencial dentro do contexto educacional apontado há mais de 30 anos, como expõe Borba (2016). No entanto as políticas públicas não conseguiram levar as tecnologias para a realidade da sala de aula, embora apontem tal necessidade em documentos governamentais. Tal fato acarreta num número significativo de pesquisas e 
iniciativas de alguns professores para inserção das TICs nas salas de aula que esbaram na questão da disponibilidade de dispositivos.

Contribuindo com essa discussão sobre verossimilhanças da inserção das TICs na sala de aula, Borba e Lacerda (2015) chegam a propor "um celular por aluno", uma ideia que pretende explorar as potencialidades do uso do dispositivo móvel pessoal do estudante, desde que com acesso à internet fornecida pela escola, na sala de aula para atividades relacionadas ao ensino de Matemática, uma vez que o mesmo já traz este equipamento para a escola. Nesta proposta os autores compreendem que muitas vezes a escola não fornece internet para acesso através dos dispositivos móveis de seus alunos por diversos motivos, ainda assim uma parcela dos alunos se mantém conectada à rede através dos pacotes de dados móveis fornecidos pelas empresas de telefonia celular e, na maior parte das vezes em que os estudantes se conectam, não fazem isso com propósito relacionado à aula.

A presença significativa dos smatphones nas salas de aula pode ser confirmada por pesquisas como a elaborada pelo Centro de Estudos sobre as Tecnologias da Informação e da Comunicação (CETIC), denominada "TIC Educação 2016", a qual aponta um avanço significativo no uso de dispositivos móveis frente a computadores na educação, ou seja, o telefone celular foi o principal dispositivo para acesso à Internet com objetivo de pesquisas e estudos, para 93\% dos alunos usuários da rede e, em relação aos professores, $46 \%$ utilizam os celulares para acessar a internet no desenvolvimento de atividades com alunos nas escolas públicas (CETIC.BR, 2017).

Desta forma, vislumbra-se nos dispositivos móveis uma alternativa para se inserir as TICs na sala de aula e, em particular, na sala de aula de Matemática, ao ponto que também se entende que: "Um celular por aluno pode quebrar com a ideia de levarmos os alunos a algum lugar! Ao contrário, podemos ir onde eles estão: no celular inteligente!" (Borba e Lacerda, 2015, p.504). Ou seja, ao ponto que se compreende que os DMP estão presentes entre os alunos na sala de aula, surge a possibilidade de se inserir as TICs na sala de aula de Matemática fazendo uso deles.

Ainda assim, é importante esclarecer que o uso de dispositivos móveis na sala de aula não se trata da simples liberação para que tais equipamentos sejam manuseados por alunos durante a aula, mas que ele esteja diretamente relacionado ao processo educativo dentro e fora da sala de aula. Isto partindo do entendimento da UNESCO de aprendizagem móvel: "envolve o uso de tecnologias móveis, isoladamente ou em combinação com outras tecnologias de informação e comunicação (TICs), a fim de permitir aprendizagem a qualquer lugar." (UNESCO, 2014, p.7)

Enfim, os dispositivos móveis estão nas salas de aula, representados, principalmente, pelos smartphones, o que impulsiona esta discussão a avançar no sentido de refletir sobre como eles podem ser integrados no ensinar e aprender.

\section{Bases teóricas: aprendizagem móvel e educação financeira escolar}


A apresentação das bases teóricas será iniciada pela argumentação sobre a aprendizagem móvel, uma vez que já foi apresentada na seção 2 a disponibilidade das tecnologias móveis para uso na sala de aula, de posse dos alunos e uso pelos professores. Em seguida, a proposta de Educação Financeira Escolar que norteia esta investigação é apresentada, além de ser destacados os pontos importantes sobre a tomada de decisão que é um dos elementos principais neste contexto.

\subsection{Aprendizagem móvel}

Liberar ou proibir o uso dos smartphones nas salas de aula? Acredita-se que esta não é a pergunta correta, nem tampouco é simples sua resposta. O que é defendido aqui é que as tecnologias móveis sejam sim integradas aos processos de ensino e aprendizagem na sala de aula e, para tal, busca-se entender melhor a aprendizagem móvel uma vez que se constata a presença de tal tecnologia com os alunos.

Ter um pequeno computador à disposição das pessoas a todo instante e lugares levou alguns pesquisadores a discutirem a inclusão de tais dispositivos nos contextos de ensino e da aprendizagem. Tais discussões culminaram em alguns entendimentos sobre a "aprendizagem móvel", "aprendizagem com mobilidade" ou m-learning, mobile learning como no original em língua inglesa. Atentando-se a isto, esta investigação traz as definições presentes sobre a aprendizagem instrumentada por dispositivos móveis a fim de retomar o termo no final desta sessão elucidando nosso compromisso teórico.

A aprendizagem móvel é exposta por Mülbert e Pereira, (2011, p.2) como "o conceito que representa a aprendizagem entregue ou suportada por meio de dispositivos de mão tais como PDAs (Personal Digital Assistant), smartphones, iPods, tablets e outros pequenos dispositivos digitais que carregam ou manipulam informações", neste sentido é destacado pelos autores a grande questão que diferencia este formato de outros: a tecnologia utilizada possibilita que o estudante, em qualquer lugar e hora, tenha acesso a informações ou as produza de modo que haja aprendizagem usando variados recursos num só dispositivo.

Num contexto de aprendizagem móvel não se pode deixar de lembrar que é preciso ter bem definido qual o propósito com o qual os DMP dos alunos (e do professor) serão inseridos na aula, a fim de que todos participem do processo de ensino e de aprendizagem. Neste contexto, Moura (2009, p.58) justifica afirmando já que "os telemóveis são cada vez mais um mini computador não faz sentido a sua não inclusão." E reforça que, a resistência a tecnologias digitais na sala de aula, em particular, de matemática não é algo novo: "Agora são os telemóveis, antes eram as calculadoras".

Apresentar um conceito recente de aprendizagem móvel não significa que ela não ocorria até então. Isto se pode observar com Moura (2009) que apresenta algumas iniciativas para a inserção dos dispositivos móveis num contexto de aprendizagem. Algumas delas ocorreram na África ao se perceber que o uso de computadores era restrito, mas o de dispositivos móveis viável por seu baixo custo e ampla oferta no mercado. De forma semelhante, no Brasil, o uso de DMP mostra-se viável por exigir menos investimentos da ou na instituição de ensino, isto considerando que não será necessária a compra de tais equipamentos, pois eles já estão de posse dos alunos. Assim como verificado em Moura 
(2009, p.74) dentro de seu contexto, também se entende que "a escola apenas tem de aproveitar o facto dos alunos terem na sua mão um mini computador pago pelos pais, que ao pretenderem controlar os filhos lhes estão a dar para as mãos uma independência gigante". Contudo, é importante ressaltar que não se afirma com isso a inexistência da necessidade de se investir em programas de formação continuada para que o professor venha inserir as tecnologias na sua prática docente, em infraestrutura de redes para que tanto os professores quanto os estudantes possam acessar à internet e em tantos outros aspectos que as instituições de ensino necessitam.

Como Moura (2009) aponta, em sua revisão de literatura, em relação ao uso dos dispositivos móveis: na Nigéria, contribuiu com um aumento nos índices de alfabetização; na África do Sul disponibiliza conteúdo matemático aos alunos e; é utilizado na Educação a Distância no Quênia. Ele também destaca que o uso dos dispositivos móveis, ou "telemóveis" em suas palavras, no contexto educativo deve explorar suas diversas funcionalidades, tais como: calculadora; calendário; câmera (foto ou filmagem); reprodutor/gravador de áudio; bloco de notas; navegador de internet. Ou seja, evitando limitar-se a apenas uma delas, ao ponto que considera o dispositivo móvel "como um "canivete suíço" mas, se o usarmos só para abrir cápsulas, estamos a desperdiçar as suas potencialidades". (MOURA, 2009, p.26).

Embora Borba e Lacerda (2015) defendem que o acesso à internet é importantíssimo ao se inserir os dispositivos móveis dos alunos em atividades na aula de Matemática, posto que dela emergem inúmeras possibilidades de investigações e tarefas a serem realizadas com os estudantes. Os autores reconhecem que há uma resistência das escolas em liberar o acesso à sua rede de internet aos alunos e, por outro lado, não se pode contar que os alunos tenham dados móveis (planos de acesso à internet com rede através de suas operadoras de telefonia) disponíveis para uso em aula, uma vez que isso envolve custos.

Frente a isto, entende-se que a inclusão dos dispositivos móveis na sala de aula de Matemática deve ocorrer com ou sem acesso à internet. Isto consoante a observação feita por Moura (2009, p.75) que sendo inviável disponibilizar acesso à internet para os estudantes "é possível usar os serviços standards que os telemóveis oferecem, como complemento ao processo de ensino e aprendizagem".

Diante dos autores aqui expostos, fica entendido que a aprendizagem móvel é todo processo no qual o sujeito aprende instrumentado por dispositivos de tecnológicos que acompanhe o sujeito da aprendizagem por diversos espaços e em parte significativa de seu tempo. E, esclarece-se que a expressão instrumentado é aqui empregada consoante a concepção de Vigotsky, já a aprendizagem é entendida, sob a perspectiva do Modelo dos Campos Semânticos enquanto produção de "ações enunciativas a respeito de um objeto no interior de uma atividade". (SILVA; LINS, 2013, p.5).

Uma vez demonstradas as bases teóricas sobre as quais se sustenta esta discussão sobre a integração das tecnologias móveis com o ensinar e aprender na sala de aula, considerando a expansão deste espaço para outros em que o estudante transite, será dada sequência na exposição da proposta de Educação Financeira Escolar assumida, por ser objeto de discussão da tarefa elaborada. 


\subsection{Educação Financeira Escolar (EFE)}

A discussão sobre o uso da tecnologia aqui levantada passa por sua inserção nos processos de ensino e de aprendizagem imersa em tarefas, na análise particular aqui realizada, de Educação Financeira Escolar. Portanto dedica-se esta seção para elucidar sobre o que se assume enquanto Educação Financeira Escolar e alguns conceitos que foram indispensáveis na elaboração e aplicação da tarefa analisada.

Neste sentido, já se deixa claro que a Educação Matemática discutida e praticada, assim como a Educação Financeira Escolar que é parte desta, deve estar articulada indissociavelmente da sociedade em que se está inserida. E, tratando-se da sociedade contemporânea, uma de suas características que vem chamando muito atenção de diversos pesquisadores é o consumismo, pois, segundo Bauman (2008),

[...] é um tipo de arranjo social resultante da reciclagem de vontades, desejos e anseios humanos, rotineiros e permanentes e, por assim dizer "neutros quanto ao regime", transformando-os na principal força propulsora e operativa da sociedade, uma força que coordena a reprodução sistêmica, a integração e a estratificação sociais, além da formação de indivíduos humanos, desempenhando ao mesmo tempo um papel importante nos processos de auto-identificação individual e de grupo, assim como na seleção e execução de políticas de vidas individuais. (p.41).

Além do apontado em Bauman (2008), fica notório a precedência do consumo à análise da real necessidade ou possibilidade de realização deste, uma vez que se leva em consideração os dados da Pesquisa de Orçamentos Familiares 2008-2009 realizada pelo IBGE: $75 \%$ das famílias brasileira tem dificuldades em chegar ao final de um mês com seus rendimentos (IBGE, 2010). Apesar desta pesquisa não ser atual, ela é uma das mais recentes análises deste tipo divulgada pelo instituto.

Outra análise importante nesta leitura da relação da sociedade com as finanças é a Pesquisa Nacional de Endividamento e Inadimplência do Consumidor (Peic) - realizada pela Confederação Nacional do Comércio de Bens, Serviços e Turismo (CNC) -, ela aponta que "o percentual de famílias que relataram ter dívidas entre cheque pré-datado, cartão de crédito, cheque especial, carnê de loja, empréstimo pessoal, prestação de carro e seguro alcançou 58,7\% em maio de 2016" (CNC, 2016, p.1), e o mais assustador é o seguinte dado: somente $9 \%$ das famílias tem condições de quitar tais dívidas.

Neste contexto social de consumo urgente, faz-se impreterível a discussão sobre finanças nas salas de aula, tendo este ambiente o papel de sediar reflexões sobre algumas das variáveis que estão relacionados à compra, venda, trocas, doações, descarte ou qualquer outra transação com algum valor financeiro a ele agregado.

Diante deste cenário, conclui-se que a sociedade urgia por uma educação financeira de seus indivíduos que não esteja limitada a operar fórmulas para atender às listas de exercícios. E, é de tamanha importância a discussão de tal temática que Organização para Cooperação e Desenvolvimento Econômico (OCDE) tem se posicionado reforçando este discurso a ponto de destacar vantagens sociais e individuais decorrentes de uma comunidade educada financeiramente. No entanto, o maior esforço desta organização 
internacional é instruir as pessoas de seus países membros desde o início de sua escolarização, mas num contexto de finanças pessoais, em que profissionais de diversas áreas podem atuar abordando a temática, segundo Silva e Powell (2015).

Diante do reconhecimento da relevância que a temática seja levada à população, sendo uma as principais vias para isto a sala de aula da Educação Básica, entende-se que, neste rico espaço de discussão que é a escola, não se deve limitar Educação Financeira a finanças pessoais. Por conseguinte, ao buscar uma concepção que atendesse a tais necessidades observadas, encontrou-se a Educação Financeira Escolar proposta Silva e Powell (2013), uma asserção integrada à Educação Matemática e elaborada considerando realidade da escola. Nela fica compreendido que:

A Educação Financeira Escolar constitui-se de um conjunto de informações através do qual os estudantes são introduzidos no universo do dinheiro e estimulados a produzir uma compreensão sobre finanças e economia, através de um processo de ensino que os torne aptos a analisar, fazer julgamentos fundamentados, tomar decisões e ter posições críticas sobre questões financeiras que envolvam sua vida pessoal, familiar e da sociedade em que vivem. (SILVA; POWELL, 2013, p.12).

Esta compreensão de Educação Financeira Escolar dá total suporte a se discutir o assunto de forma interligada às práticas sociais de cada comunidade, posto que se assume a inexistência de um modelo financeiro-econômico de um determinado grupo social que deve se sobrepor a qualquer outro, isto é, diversos modelos podem ser estudados e inclusive coexistirem dada a aceitação pelo grupo social em que é dada a discussão. Isto já deixa evidente que o currículo defendido deve estar flexível diante desta realidade.

Dentro desta concepção de Educação Financeira Escolar, é dado destaque à tomada de decisão posto que, além de ser citada na definição exposta, é tema de discussão da tarefa aqui apresentada, "é uma das principais ações na direção de uma cidadania crítica" (MUNIZ JUNIOR; JURKIEWICZ, 2016, p.79) e por decisões que envolvem finanças ocorrerem no cotidiano de inúmeras, senão todas, pessoas, mas sem que estas façam uma análise, ainda que rápida, sobre suas escolhas e, neste sentido, vale retomar a afirmação de Muniz Junior e Jurkiewicz (2016, p.86): "uma questão central da Educação Financeira Escolar seja o valor do dinheiro no tempo e seus efeitos na tomada de decisão das pessoas".

Vários fatores motivam a aquisição ou a não-aquisição de bens ou serviços, tais fatores não são de simples compreensão, principalmente à medida que se entende que na sociedade líquido-moderna o consumo deixou de ser um ato individual passando a ser uma ação social (BAUMAN, 2008). Além dos fatores relacionados à aquisição, também há outra escolha a ser feita a de como e quando o objeto de consumo será adquirido. Neste aspecto já começam a aparecer elementos que permitem a análise do comportamento do valor do dinheiro e/ou objeto de consumo ao longo do tempo.

Adentrando mais neste ambiente, a forma de pagamento tem se tornado uma decisão cada vez mais complexa diante dos diversos produtos oferecidos pelo mercado financeiro. Sendo assim, limitar a análise de compra a verificação do saldo em conta diante do valor que se pretende gastar, tornou-se uma análise minimalista, tendo em vista que isso 
se reflete, em parte, no número de famílias brasileiras endividadas.

Não há tempo e/ou pouco se sabe como analisar a influência da inflação, a rentabilidade de poupança ou algum investimento, talvez se olhe o histórico de preço do produto, mas o mais comum é a comparação de preço entre lojas diferentes, quando isso ocorre. Todos esses pontos citados, e outros não citados, poderiam fazer parte da avaliação feita para a tomada de decisão.

O cenário é desafiador, mas a tarefa aqui exibida busca trazer elementos que auxiliem a análise do estudante para sua tomada de decisão em situações que envolvam o dinheiro, de forma a assumir com Muniz Junior e Jurkiewicz (2016, p.79) que "os aspectos matemáticos aparecem conectados a aspectos não matemáticos no processo de tomada de decisão, formando uma teia de significados para as situações apresentadas".

Um bom exemplo do esforço em tratar a Educação Financeira no âmbito da matemática apresentada no ensino médio está o trabalho de Silva e Selva (2018), que busca identificar nos livros do professor se há orientações para o desenvolvimento das atividades propostas para o aluno e se estas indicam o trabalho das questões a partir da matemática. Como contribuição, as autoras concluíram que as atividades de educação financeira, propostas no livro do aluno, podem proporcionar contextualização do ensino de matemática e sugerem que o trabalho se dê a partir da realidade dos alunos.

A partir da reflexão sobre a sociedade contemporânea que se assumiu tal proposta de Educação Financeira Escolar e seus desdobramentos. Tal posicionamento determinou as diretrizes tanto na produção quanto na forma com que se aplicou a tarefa na sala de aula, como é descrito a diante.

\section{Seleção do aplicativo, produção e aplicação da tarefa}

Partindo do entendimento que não basta liberar o uso dos dispositivos móveis trazidos pelos alunos para dentro da sala de aula, mas é necessário ter uma proposta pedagógica que integrem os mesmos aos processos de ensino e aprendizagem, será apresentada uma forma em que é possível inferir sobre esta integração: produção e aplicação de tarefas. Destacando-se que na produção de tarefas é fundamental que aplicativos sejam selecionados a fim de serem sugeridos para uso dos estudantes, portanto esta apresentação começará por tal seleção.

\subsection{Processo de seleção do aplicativo}

Uma vez que se assume convidar os estudantes a usarem seus dispositivos móveis para se envolverem numa tarefa, é de suma importância se atentar em alguns fatores: a quantidade de alunos que possui esse equipamento e o leva para a escola; qual é o sistema operacional em uso na maioria dos dispositivos dos alunos; se há internet disponível para uso durante a aula e, havendo, que tipo de rede é usada (da instituição ou particular do aluno). 
Conhecida a realidade da sala de aula quanto a posse dos dispositivos móveis, avança-se para discutir sobre os critérios para seleção do aplicativo a ser indicado pelo professor aos seus alunos para ser usado durante o envolvimento com a tarefa. É importante deixar claro desde já que a proposta feita aqui sugere ao professor indicar um ou alguns aplicativos, mas não assuma estes como de uso indispensável ou exclusivo durante a tarefa, pois esta postura pode anular um dos mais relevantes atributos dessa tecnologia que é a multifuncionalidade.

Já existem alguns critérios de qualidade intrínsecos para aplicativos educacionais consolidados por pesquisas nacionais e internacionais, entretanto, conforme Andrade, Araujo Jr. e Silveira (2017), a maior ênfase deve ser dada a definição do uso do aplicativo e, a partir daí se atentar aos critérios de seleção.

Para Dias e Araújo Jr. (2014) e Saccol, Schlemmer e Barbosa (2011) apud Andrade, Araujo Jr. e Silveira (2017) os critérios de qualidade são:

Requisitos pedagógicos - ambiente educacional, aspectos didáticos, pertinência ao programa curricular); Usabilidade - facilidade de uso, de aprendizagem; Interatividade - o usuário é protagonista no uso dos recursos, fazendo escolhas que levam a experiências e resultados diferentes; Acessibilidade - personalização, adequação ao ambiente; Flexibilidade - adequação tecnológica e adaptação às necessidades e preferências dos usuários e ao ambiente educacional; Mobilidade considerando a portabilidade (equipamento de fácil manuseio em diversos lugares e situações) e a geolocalização (serviços integrados à identificação do local de onde são acessados); Ubiquidade - integração dos alunos aos seus contextos de aprendizagem e a seu entorno; Colaboração - ambiente de colaboração, participação e interação entre alunos, professores e instituições; Compartilhamento - socialização do desenvolvimento das atividades, bem como dos resultados das atividades entre os demais alunos, professores e instituição; Reusabilidade - capacidade de ser utilizado em variados contextos e situações de aprendizagem e com alunos de diferentes perfis. (p.187).

Para a tarefa proposta nesta investigação, a questão problematizada enquanto elemento a ser analisado para a tomada de decisão foi a variação do valor do dinheiro no tempo e, neste sentido, foram levantadas situações nas quais o dinheiro é aplicado a fim de gerar rendimentos e também para se analisar os reflexos da inflação nos preços. Diante dessas situações atentou-se para a seleção de aplicativos que apoiariam os alunos através de simulações.

Os aplicativos escolhidos, foram obtidos através de pesquisa no Google Play que é a loja oficial de aplicações para sistema operacional Android. A escolha por este sistema justifica-se pelo número expressivo de smartphones e/ou tablets comercializados no Brasil entre março e abril de 2017 e que possuíam o sistema Android ${ }^{1}$, chegando a corresponder a $92,1 \%$ das vendas no período. Outra opção de escolha possível e que deve ser considerada é de pesquisar na sala de aula o tipo de sistema instalado nos dispositivos dos alunos e a partir disso, fazer a busca, selecionar e sugerir os aplicativos para uso.

\footnotetext{
1 Resultados de pesquisa disponível em https://www.kantarworldpanel.com/global/smartphone-os-market-share/, acessado em 05 de junho de 2017.
} 
Aplicando os critérios de seleção foi possível preencher dois quadros da seguinte forma: para preenchimento do Quadro 1 (requisitos pedagógicos), julgou-se necessário que o aplicativo permitisse calcular o valor futuro e o montante do valor em aplicação com depósitos regulares; no preenchimento do Quadro 2 seguiu-se os requisitos técnicos.

De forma sucinta faz-se um recorte do quadro apenas com a análise dos aplicativos selecionados, ou seja, do "Calfi - calculadora de juros" e da "Calculadora do Cidadão".

Quadro 1: Verificação dos assuntos abordados nos aplicativos

\begin{tabular}{|c|c|c|}
\hline & \multicolumn{2}{|c|}{ O Aplicativo permite calcular: } \\
\hline Aplicativo & Valor Futuro & $\begin{array}{c}\text { Aplicação com depósitos } \\
\text { regulares }\end{array}$ \\
\hline Calfi - calculadora de juros & Totalmente & Parcialmente \\
\hline Calculadora do Cidadão & Totalmente & Totalmente \\
\hline
\end{tabular}

Fonte: Fernandes (2018)

Quadro 1: Aplicação dos critérios para seleção do aplicativo

\begin{tabular}{|l|c|c|}
\hline \multirow{2}{*}{ Requisitos } & \multicolumn{2}{|c|}{ Aplicativos } \\
\cline { 2 - 3 } Usabilidade & Calfi & Calculadora do Cidadão \\
\hline Interatividade & Atende Totalmente & Atende Totalmente \\
\hline Acessibilidade & Atende Totalmente & Atende Totalmente \\
\hline Flexibilidade & Não Atende & Não Atende \\
\hline Mobilidade & Atende Parcialmente & Atende Parcialmente \\
\hline Ubiquidade & \multicolumn{2}{|c|}{ Não se aplica } \\
\hline Colaboração & Atende Parcialmente & Narcialmente \\
\hline Compartilhamento & Não Atende & Atende Totalmente \\
\hline Reusabilidade & Não Atende & Atende Totalmente \\
\hline
\end{tabular}

Fonte: Fernandes (2018)

Apesar dos aplicativos não terem funções específicas destinadas a colaboração, entende-se que a ela é inerente às relações sociais existentes entre os membros de um grupo, desta forma, ela tem grandes chances de acontecer durante a tarefa independente do aplicativo. Uma diferença que se pode evidenciar entre os dois aplicativos é que o Calfi apresenta a seu usuário o passo a passo das operações realizadas para se alcançar o resultado final da simulação, enquanto o Calculadora do Cidadão se resume em exibir apenas o resultado. Mas isto são apenas diferença entre eles, o que torna um melhor que o outro é a situação em que serão inseridos, pois eles têm propostas de uso diferentes.

\subsection{Produção da tarefa}


Ao se tratar sobre a produção de tarefas é importante compreender que este é um assunto distinto da modelagem Matemática, resolução de problemas e dos exercícios contextualizados presentes nos livros didáticos, pois a preocupação dessas, na maioria das vezes, transparece ser alcançar uma resposta compreendida como correta. Desta forma, apresenta-se a principal distinção destas propostas com a de produção de tarefas, posto que o objetivo central desta é estimular a produção de significados, isto é, que o aluno aprenda consoante a perspectiva do Modelo dos Campos Semânticos em Silva e Lins (2013).

Na elaboração da tarefa, é de suma importância considerar que os estudantes devem utilizar seus dispositivos móveis durante seu envolvimento, uma vez que é assumido que a tecnologia móvel só é eficazmente inserida nos processos de ensino e de aprendizagem quando há um planejamento para isto, ou seja, a tarefa é construída com a intenção de que a tecnologia seja utilizada. Sendo assim, é interessante para a elaboração de tarefas assumir algumas características para nortear este processo. Neste caso, assumiu-se as seguintes características apontadas por Fernandes (2018) a partir das leituras dos textos de Loth (2011):

As tarefas são projetadas para serem utilizadas em salas de aula reais de matemática em que os estudantes possuem voz audível. Isto é, uma sala de aula de matemática onde a fala dos alunos é respeitada e; as tarefas deverão levar os alunos a ler além do texto fornecido em sala de aula, impulsionando-os a buscar informação em outros espaços, sejam físicos ou virtuais. (FERNANDES, 2018, p.39).

Ainda, pautou-se em mais características expostas por Loth:

As tarefas serão elaboradas considerando contextos que permitam ao aluno aprender matemática produzindo significados que vão além da matemática a partir da análise do que os números podem trazer de informações. O contexto não é usado com o intuito de motivar os alunos, mas para colocar o aluno em contato com assuntos relevantes que possam propiciar reflexões e debates.; as tarefas devem permitir que o aluno experiencie situaçõesproblema que não possuam apenas uma única resposta, mas que possibilite explicitar os diferentes modos de produção de significados de cada um deles, além de estimular a sua tomada de decisão em muitos momentos da atividade e; tecnicamente, seguindo uma conduta dos pesquisadores que têm o MCS como referencial teórico, buscamos ao máximo que cada tarefa tivesse como características ser familiar e não usual. Pois essas características auxiliam muito na observação da produção de significados de uma pessoa que se propõe falar a partir daquele enunciado. (LOTH, 2011, p.78).

A partir destes pontos norteadores, desenvolveu-se um conjunto de quatro situações, que juntas compõem a tarefa: À vista ou à prazo: dois lados de uma mesma moeda", as quais sugere-se que ocorram em três encontros com uma turma de alunos do primeiro ano do Ensino Médio. 


\section{À vista ou à preazos dois lados de uma mesma moeda}

Figura 1: Layout da tarefa Fonte: Fernandes (2018)

Situação 1: Discussão sobre formas de pagamento (parcelado x à vista)

No primeiro encontro, propõem-se trabalhar com os alunos o assunto finanças a fim de abrir a discussão, em seguida, sugere-se propor uma questão quanto às formas de pagamento (à vista ou parcelado), conforme a sequência de slides da pesquisa de Fernandes (2018).

\section{Situação 2: Apresentação do caso de "Ramon"}

Uma vez agrupados, dar-se-á início ao processo colocando o caso de "Ramon", um jovem estudante/trabalhador que, já possui um computador em sua casa, mas de um modelo que está ficando ultrapassado e, portanto, decide comprar um notebook novo. Diante disto ele está em dúvida sobre juntar o dinheiro e comprar à vista ou optar pelo pagamento a prazo, conforme apresentado na Figura 3.

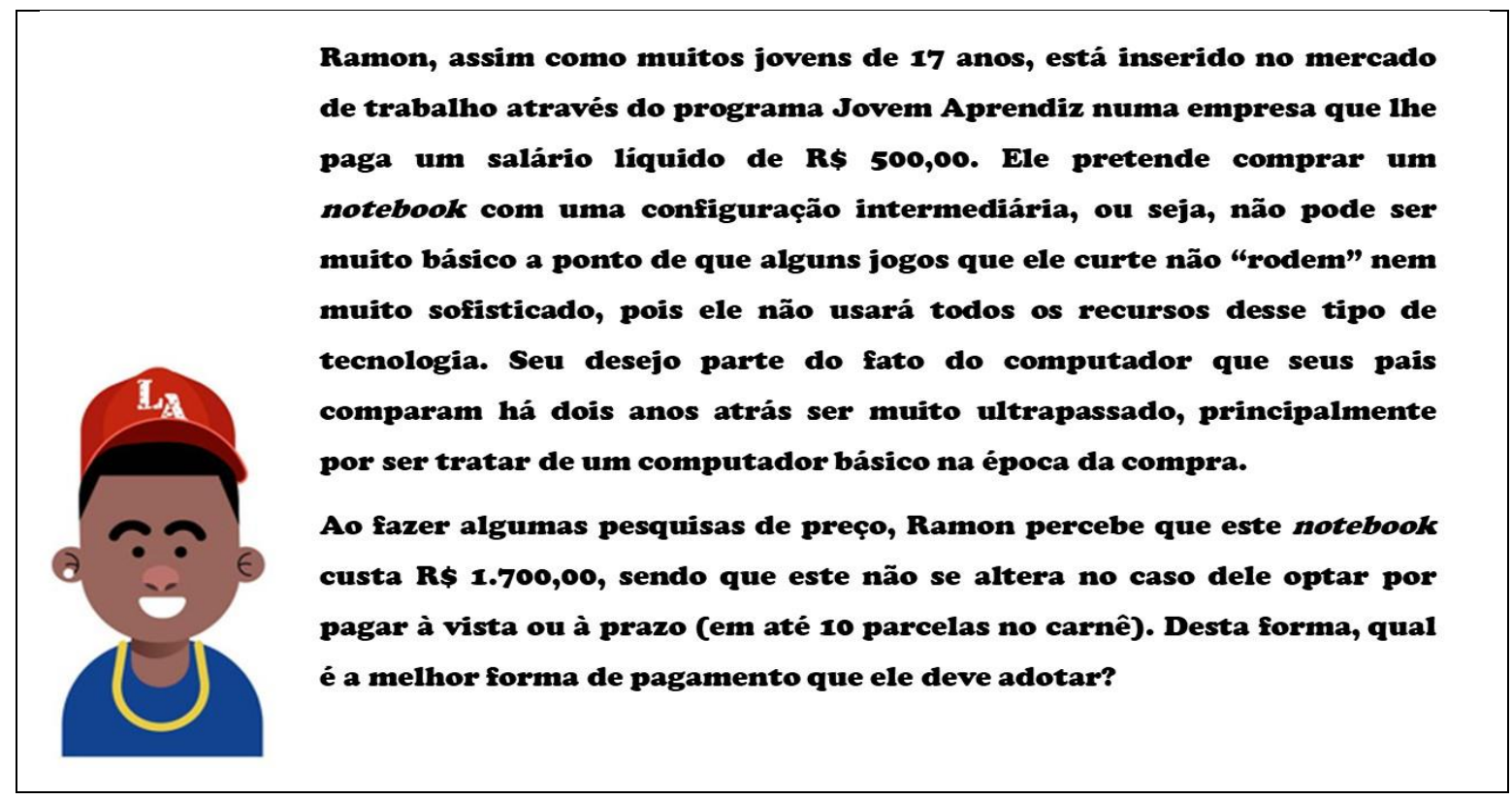


Pautando-se na realidade dos estudantes envolvidos na pesquisa é construído o personagem com as seguintes características: "estudante/trabalhador", pois muitos jovens da periferia que, por vezes, entram no mercado de trabalho, formal ou informal, por diversas razões que vão desde levantar um "dinheirinho extra" à necessidade de ajudar na composição da renda familiar; tendo remuneração ( $R$ \$ 500) consoante à realidade do mercado de trabalho que costuma absorver estes estudantes; o produto (notebook) é familiar, sendo objeto de desejo de uma parcela significativa deles, no entanto é importante tomar cuidado com esta abordagem, posto que o objetivo não é instigar os alunos ao consumismo, mas apenas trazer um contexto próximo a realidade deles para que a discussão não se dê apenas no imaginário.

O preço do produto será discutido com os alunos, estimulando sua análise do mercado, deixando claro a eles que será comprado um notebook dentro de uma categoria de configuração, entendendo-se que um notebook de configuração intermediária hoje será considerado de configuração básica daqui a um ano, por exemplo. Ou seja, se "Ramon" não comprar um de configuração intermediária hoje, deverá juntar dinheiro de forma que compre um com configuração intermediária no final do período no qual decidiu fazer o acúmulo.

Colocada a situação de "Ramon", presente na Figura 3, é aberta a discussão com o grupo com propósito de que seja percebido "de onde" fala o estudante, isto é, que significados produz a partir da situação problema e que decisão ele tomaria no lugar do personagem da tarefa. Entendendo que, saber o lugar do qual o aluno parte na produção de significados ao longo de um processo é de suma importância na análise dos caminhos tomados durante o desenvolvimento do conjunto de tarefas.

Uma vez que os alunos forem ouvidos, elementos serão introduzidos na discussão, caso já não o forem pelos estudantes, tais como: alguns impactos do comportamento adotado ao se lidar com o dinheiro na vida das pessoas (num contexto individual, familiar e/ou social); alguns aspectos em que é vantajoso parcelar o valor de uma compra; e dados que apontam uma forte relação do endividamento das famílias com o uso do cartão de crédito (provavelmente para postergar ou parcelar pagamentos). A partir deste novo elemento, é continuada a discussão, atentando-se para a produção de significado dos alunos sob (ou sem) influência do material apresentado.

Finalizando este primeiro encontro, tendo em vista que a maioria das escolas brasileira possui acesso à internet, mas não disponibiliza aos estudantes, sugere-se que seja solicitado aos estudantes que pesquisem na internet de suas residências ou dispositivos móveis o que se fala sobre vantagens e desvantagens das compras à vista $\mathrm{e}$ a prazo, trazendo o conteúdo encontrado para a discussão do próximo encontro.

Situação 3: Investimentos e inflação

No encontro seguinte, logo em seu início, os estudantes devem ser ouvidos a 
respeito do que pesquisaram e do que produziram de significado a partir desta ação. Se os dados encontrados pelos estudantes não trouxerem elementos como investimentos e inflação, a questão será levantada através de uma apresentação de slides (Figura 4) com situações hipotéticas para que simulações sejam necessárias para se analisar a "vantagem" obtida pela forma de compra, caso tais elementos cheguem à discussão através dos alunos, a simulação será feita a partir destes.

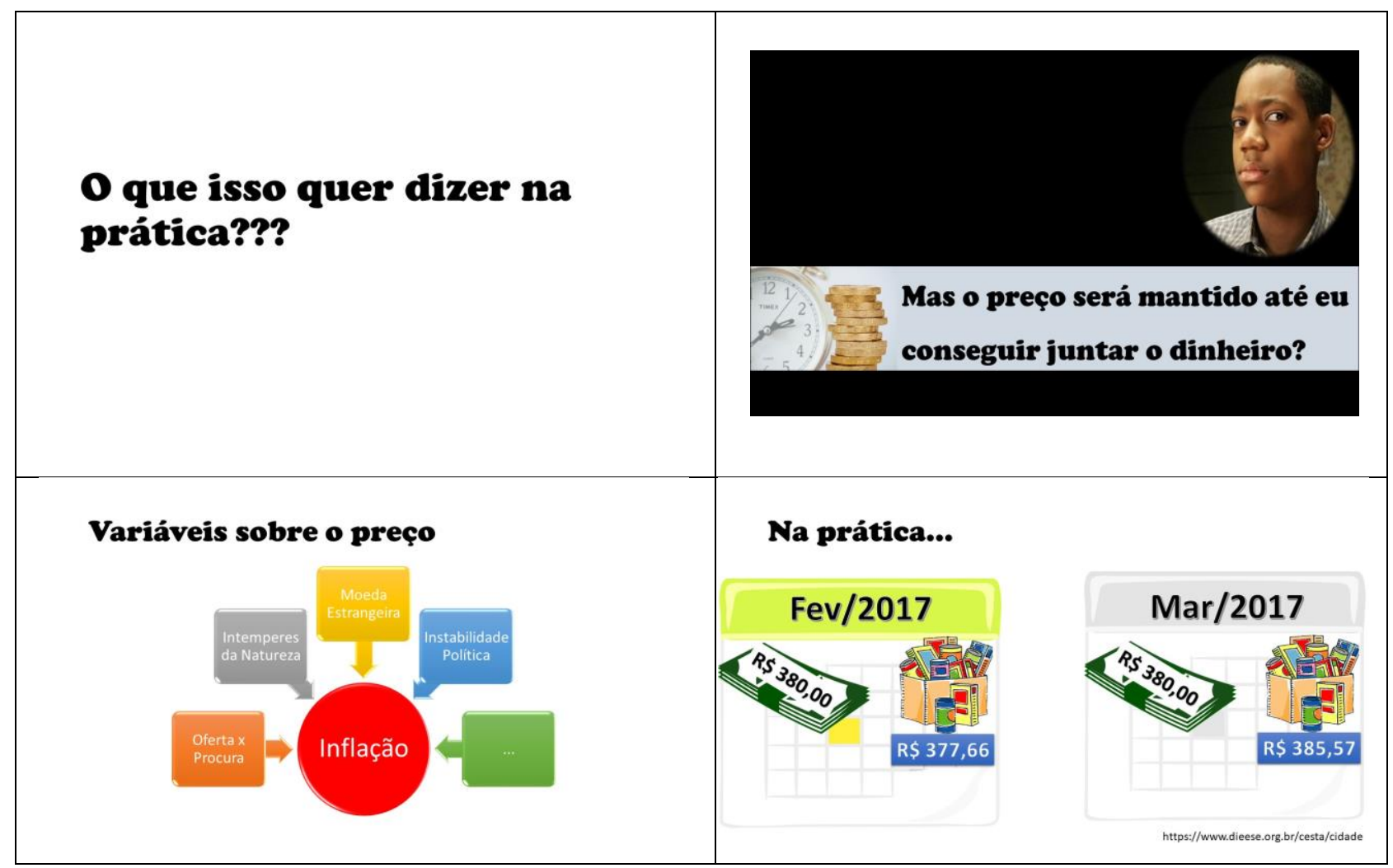

Figura 4: Situação 3: Investimentos e inflação Fonte: Fernandes (2018)

Neste momento será apresentada e problematizada uma forma de se expressar a variação do valor do dinheiro no tempo. Apresentada, ao pressupor que ela não é de conhecimento dos estudantes, e problematizada a medida que se propõe discutir com os alunos a usabilidade dela no cotidiano para se decidir entre comprar à vista ou a prazo. Contextualizados, deverão caminhar para uma solução que seja viável no dia-a-dia, sendo assim, o aplicativo (descrito em detalhes a seguir) deverá ser introduzido enquanto mediador no processo de compreensão deste fenômeno (variação do dinheiro no tempo).

Situação 4: Uso dos dispositivos móveis (aplicativo)

No terceiro e último encontro, os alunos serão colocados novamente diante da situação de "Ramon" para que, a partir dos elementos inseridos ao longo do processo, possam reavaliar a situação a ponto de manter ou alterar sua opção inicial de aconselhamento sobre comprar à vista ou a prazo. E é neste cenário que o professor deverá 
estar atento para os argumentos apresentados pelos alunos, justificados ou não, pois eles dizem muito sobre o que de fato se aprendeu neste contexto de discussão.

A expectativa é que o ambiente seja propício para se perceber o papel desempenhado pelo aplicativo indicado, tanto no processo como um todo e principalmente, neste momento da tarefa, pois nele é que o aluno deverá se posicionar e tomar sua decisão à medida que compreende uma forma de pagamento melhor em detrimento de outra.

Apesar de se destacar o uso de dois aplicativos no processo, entende-se que o dispositivo móvel poderá ser explorado pelas suas mais diversas funcionalidades o que será decorrente da forma particular da interação que cada aluno com tem com esta tecnologia, o que, certamente, também poderá ser objeto de análise. Ou seja, os dispositivos móveis poderão ser utilizados, por exemplo, para acessar a internet a fim de se obter as taxas atuais de inflação, de rendimento da poupança ou de outro investimento, movimento enriquecedor no desenvolvimento da tarefa.

\subsection{Um exemplo de aplicação da tarefa}

A tarefa aqui exposta também foi objeto de análise da pesquisa de Fernandes (2018), a qual estruturou sua aplicação em dois encontros com uma turma de terceiro ano do Ensino Médio de uma escola pública de periferia.

Neste movimento em que o aluno envolveu-se com a tarefa instrumentado pela tecnologia móvel que possuía, eles foram capazes de tomar decisões, ou melhor, auxiliar o personagem da tarefa a tomar sua decisão, a partir da análise feita sobre elementos matemáticos e não-matemáticos decorrentes de suas vivências, das informações apresentadas na sala de aula, das simulações feitas usando o smartphone e dos dados que eles mesmos trouxeram de suas pesquisas feitas na internet.

Além deste importante resultado, é possível notar que os dispositivos móveis deram suporte aos alunos durante suas simulações, principalmente com o uso dos aplicativos sugeridos, ainda que outros, como a calculadora padrão, também fossem utilizados.

O uso de motores de busca na internet também foram utilizados dentro e fora da sala de aula, trazendo para os encontros novos elementos ou para ajudar no entendimento dos já presentes nos textos das situações colocadas pela tarefa. A colaboração surgiu pela tecnologia usada, uma vez que eles trocavam mensagens e/ou dados via bluetooth entre si dividindo os resultados encontrados, tanto nas simulações feitas quanto nas busca por dados que permitissem entender melhor as situações a que foram expostos.

Ainda assim, percebeu-se que o desenvolvimento crítico dos alunos não estagnouse com o uso dos dispositivos móveis, a ponto deles questionarem os resultados encontrados, quando divergiam as simulações entre eles e se auto criticavam quando o resultado de suas simulações Ihe eram estranhos.

Outro ponto importante destacado por Fernandes (2018) é que em seus encontros com a turma pesquisada é que o caderno foi totalmente substituído pelo smartphone pela maioria dos estudantes e, quando não houve a substituição, o papel e caneta foram usados poucas vezes por eles. Mas isto não significa que se defenda o abandono de um em 
detrimento de outro, mas que ambos devem ser aproveitados no ambiente educacional da melhor forma possível, isto é, instrumentando o estudante em sua produção de conhecimento.

\section{Considerações Finais}

As considerações aqui feitas não tem a pretensão de encerrar e muito menos de delimitar as discussões sobre os dispositivos móveis num contexto educacional, o objetivo é colaborar neste debate trazendo elementos que dialoguem com pesquisas, posicionamentos governamentais, e, principalmente, com professores que, em muitos casos, tem que lidar diariamente com a presença dos smartphones que seus alunos levam para o ambiente escolar, mas sem fazer proveito disso para sua aprendizagem.

De forma mais específica, este debate sobre o uso dos dispositivos móveis na sala de aula de Matemática não se resume ao que está aqui apresentado, e isto fica mais claro ainda quando se trata desta tecnologia num contexto de Educação Financeira Escolar, visto que ainda há poucas pesquisas que discorrem sobre o tema. Também, não se restringe a tarefas como o único meio de se integrar as tecnologias móveis presentes na sala de aula nos contexto de ensino e aprendizagem, conforme se apresentou com a tarefa "À vista ou à prazo - dois lados de uma mesma moeda", em que os estudantes foram levados a refletir sobre a tomada de decisão em ambientes que envolvem dinheiro.

Neste sentido, é razoável afirmar a existência de contribuições positivas da tecnologia móvel nos processos de ensino e de aprendizagem quando está inserida numa proposta pedagógica. E, desta forma, abre-se espaço para se explorar, por exemplo, a necessidade da formação de professores que saibam como articular tais tecnologias com suas práticas na sala de aula tanto na educação presencial quanto nas modalidades não presenciais, tanto no Ensino Básico, quanto no Ensino Técnico, Profissionalizante e/ou Superior. E, atentando-se ainda mais para o Ensino Básico, é imprescindível atentar para um projeto pedagógico que se discuta quando essa tecnologia deva ser introduzida e seus impactos na escolarização da criança.

Ou seja, é um território que já está sendo esquadrinhado, mas ainda necessita de muito trabalho neste sentido, com o intuito de os que transitarem não se percam, mas que consigam aproveitar o máximo de suas riquezas.

\section{Referências}

ALMEIDA, R.R.; ARAÚJO JR., C. F. Mobile Learning no processo de ensino e aprendizagem de conteúdos de genética: proposta e análise com base na teoria da atividade. Revista de Ensino de Ciências e Matemática (REnCiMa), v. 9, n.6, p. 56. DOI: https://doi.org/10.26843/rencima.v9i6.2089. 2018.

ANDRADE, M. V. M.; ARAUJO JR, C. F.; SILVEIRA, I. F. Estabelecimento de Critérios de 
Qualidade para Aplicativos Educacionais no Contexto dos Dispositivos Móveis (MLearning). EAD em Foco. v.7, n.2, p. 178-193. 2017.

BAUMAN, Z. Vida para o Consumo: a transformação das pessoas em mercadoria. Rio de Janeiro: Zahar. 2008.

BORBA, M. C. Fases das tecnologias digitais e a reinvenção da sala de aula. XII Encontro Nacional de Educação Matemática, p.1-4. 2016.

BORBA, M. C.; LACERDA, H. D. G. Políticas públicas e tecnologias digitais: um celular por aluno. III Fórum de Discussão: Parâmetros Balizadores da Pesquisa em Educação Matemática no Brasil, Educ. Matem. Pesq., São Paulo, v.17, n.3, p.490-507. 2015.

CNC. Pesquisa Nacional de Endividamento e Inadimplência do Consumidor (Peic). 2016. Disponível em: http://cnc.org.br/sites/default/files/arquivos/analise_peic_maio_2016.pdf. Acesso em: 23 jul. 2017.

IBGE. Pesquisa de Orçamentos Familiares 2008-2009. Rio de Janeiro. 2010.

CETIC.BR. TIC $\quad$ Educação $2014 . \quad$ Disponível em: http://data.cetic.br/cetic/explore?idPesquisa=TIC_EDU. Acesso em: 11 jul. 2017.

FERNANDES. F. D. A. Dispositivos móveis no ensino de educação financeira escolar: análise e aplicação de tarefas. 79 f. Dissertação (Mestrado em Educação Matemática) Universidade Federal de Juiz de Fora, Juiz de Fora. 2018.

LEONTIEV, A. N. Uma contribuição à teoria do desenvolvimento da psique infantil. In: Vygotsky, L. S.; Luria, A. R.; Leontiev, A. N. Linguagem, desenvolvimento e aprendizagem. 5. ed. São Paulo, SP: Icone. 1988.

LOTH, M. H. M. Uma investigação sobre a produção de tarefas aritméticas para $0 \mathbf{6}^{\circ}$ ano do ensino fundamental. 211 f. Dissertação (Mestrado em Educação Matemática) Universidade Federal de Juiz de Fora, Juiz de Fora. 2011.

MOURA, A. Geração móvel: um ambiente de aprendizagem suportado por tecnologias móveis para a "Geração Polegar". Atas da VI Conferência Internacional de TIC na Educação, 6, Braga, Portugal. 2009.

MULBERT, A. L.; PEREIRA, A. T. C. Um panorama da pesquisa sobre aprendizagem móvel (m-learning). In: V Simpósio ABCiber, Florianópolis. 2011.

MUNIZ JUNIOR, I.; JURKIEWICZ, S. Tomada de decisão e trocas intertemporais: uma contribuição para a construção de ambientes de Educação Financeira Escolar nas aulas de Matemática. Revista de Educação, Ciências e Matemática, v. 6, p. 76-99. 2016. 
NAGUMO, E. O uso do aparelho celular dos estudantes na escola. 2014. $100 f$. Dissertação (Mestrado em Educação) - Faculdade de Educação, Universidade de Brasília, Brasília. 2014.

SILVA, A. M.; LINS, R. C. Sobre a Dinâmica da Produção de Significados para a Matemática. Jornal Internacional de Estudos em Educação Matemática. v. 6, p. 1-30. 2013.

SILVA, A. M.; POWELL, A. B. Educação Financeira na Escola: A perspectiva da Organização para Cooperação e Desenvolvimento Econômico. Boletim GEPEM (Online), v. 66, p. 3-19. 2015.

SILVA, A. M. DA.; POWELL, A. B. Um programa de educação financeira para a matemática escolar da educação básica. In: Encontro Nacional de Educação Matemática, XI, 2013. Anais: Sociedade Brasileira de Educação Matemática, Curitiba. 2013.

SILVA, I. T.; SELVA, A. C. V. Programa de Educação Financeira nas Escolas - Ensino médio: Uma análise das orientações contidas nos livros do professor e suas relações com a Matemática. Revista de Ensino de Ciências e Matemática (REnCiMa), v. 9, n.1, p. 140157. https://doi.org/10.26843/rencima.v9i1.1293. 2018.

UNESCO. Diretrizes de políticas para a aprendizagem móvel. 2014. Disponível em: https://unesdoc.unesco.org/ark:/48223/pf0000227770. Acesso em: 23 jul. 2017. 